\title{
ANALYSIS OF VOLTAGE SIGNALS FROM SUPERCONDUCTING ACCELERATOR MAGNETS
}

\author{
J. Lizarazo, S. Caspi, P. Ferracin, J. Joseph, A. F. Lietzke, G. L. Sabbi, and X. \\ Wang
}

Lawrence Berkeley National Laboratory

1 Cyclotron Road, Berkeley, CA 94720

Accelerator Fusion Research Division

This document was prepared as an account of work sponsored by the United States Government. While this document is believed to contain correct information, neither the United States Government nor any agency thereof, nor The Regents of the University of California, nor any of their employees, makes any warranty, express or implied, or assumes any legal responsibility for the accuracy, completeness, or usefulness of any information, apparatus, product, or process disclosed, or represents that its use would not infringe privately owned rights. Reference herein to any specific commercial product, process, or service by its trade name, trademark, manufacturer, or otherwise, does not necessarily constitute or imply its endorsement, recommendation, or favoring by the United States Government or any agency thereof, or The Regents of the University of California. The views and opinions of authors expressed herein do not necessarily state or reflect those of the United States Government or any agency thereof or The Regents of the University of California.

This work was supported by the Director, Office of Science, Office of Fusion Energy Sciences, of the U.S. Department of Energy under Contract No. DE-AC02-05CH11231. 



\title{
ANALYSIS OF VOLTAGE SIGNALS FROM SUPERCONDUCTING
}

\section{ACCELERATOR MAGNETS}

\author{
J. Lizarazo, S. Caspi, P. Ferracin, J. Joseph, A.F. Lietzke, G.L. Sabbi and X. Wang \\ Lawrence Berkeley National Laboratory, Berkeley, CA, USA
}

\begin{abstract}
We present two techniques used in the analysis of voltage tap data collected during recent tests of superconducting magnets developed by the Superconducting Magnet Program at Lawrence Berkeley National Laboratory. The first technique was used on a quadrupole to provide information about quench origins that could not be obtained using the time-of-flight method. The second technique illustrates the use of data from transient flux imbalances occurring during magnet ramping to diagnose changes in the currenttemperature margin of a superconducting cable. In both cases, the results of this analysis contributed to make improvements on subsequent magnets.
\end{abstract}

Keywords: Superconducting magnet, voltage tap, magnet training, quench analysis 


\section{Introduction}

The Superconducting Magnet Program at Lawrence Berkeley National Laboratory is developing $\mathrm{Nb}_{3} \mathrm{Sn}$ high-field accelerator magnet technology with the purpose of providing high-performance cost-effective options for the next generation of high energy particle accelerators [1].

Efforts are underway to increase our data throughput, signal quality, and ability to extract information on the factors limiting magnet performance. Fig 1 illustrates a Magnet Voltage Monitoring System (MVMS) currently under development at LBNL [2]. Signals from voltage taps are routed into a bank of custom designed isolation amplifiers and subsequently digitized by a set of commercial digitizers. A voltage imbalance between two electrically identical halves of the magnet triggers data storage.

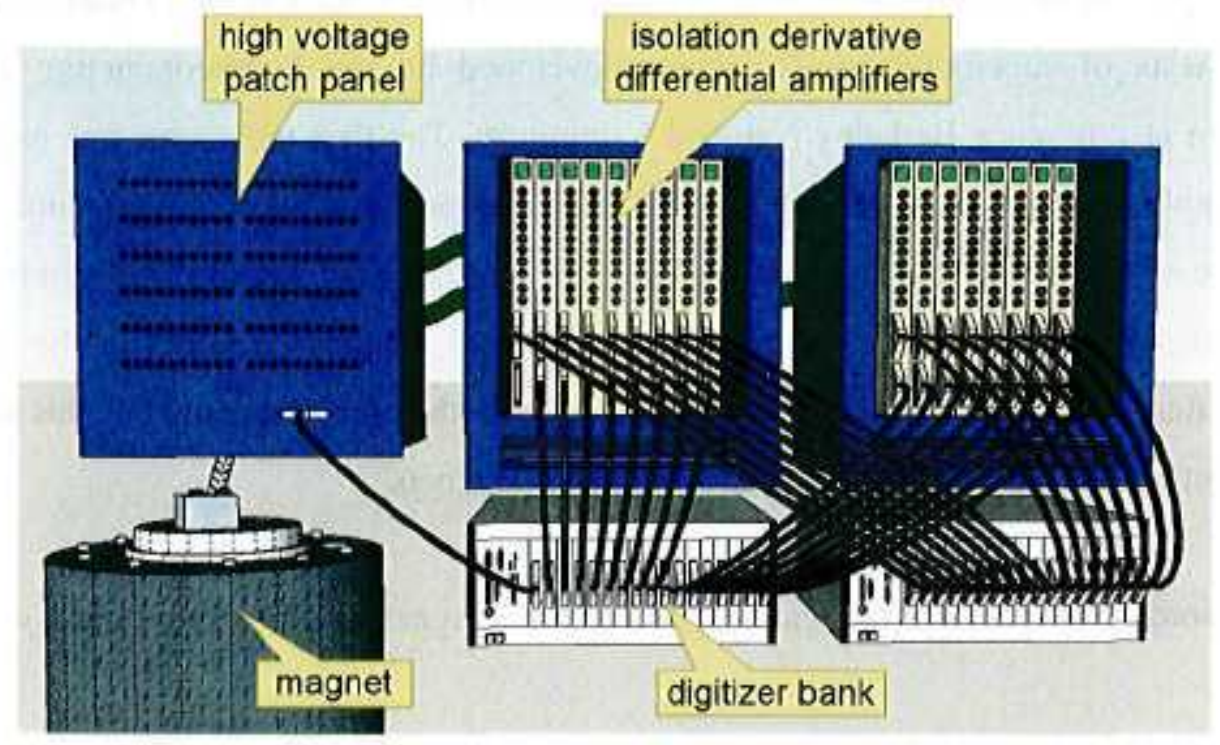

Fig 1. An electronic high-voltage patch panel (top left) routes signals from the magnet into two chassis housing high-voltage isolation amplifiers (top center and top right). At the bottom center and right are two PXI chassis housing a PC and a set of commercial digitizer modules.

The MVMS system is designed to collect data from magnet voltage taps with unprecedented resolution. Data collected is then analyzed with the purpose of providing feedback to the manufacturing process.

This article focuses on the analysis of data collected from voltage taps during magnet training. It will briefly describe the Time-Of-Flight (TOF) method to locate a quench 
origin, and then present two novel techniques that can be utilized when the TOF technique cannot be used or is not appropriate.

\section{Time-Of-Flight Quench Location Technique}

After a quench initiates, the heat generated in the normal-conducting zone causes neighboring cable sections to quench. At any given moment the time-derivative of the voltage between the two voltage taps delimiting the quenching sector is proportional to the quench propagation speed, times the number of quench-fronts propagating within the sector. Figure 2-left depicts this situation.
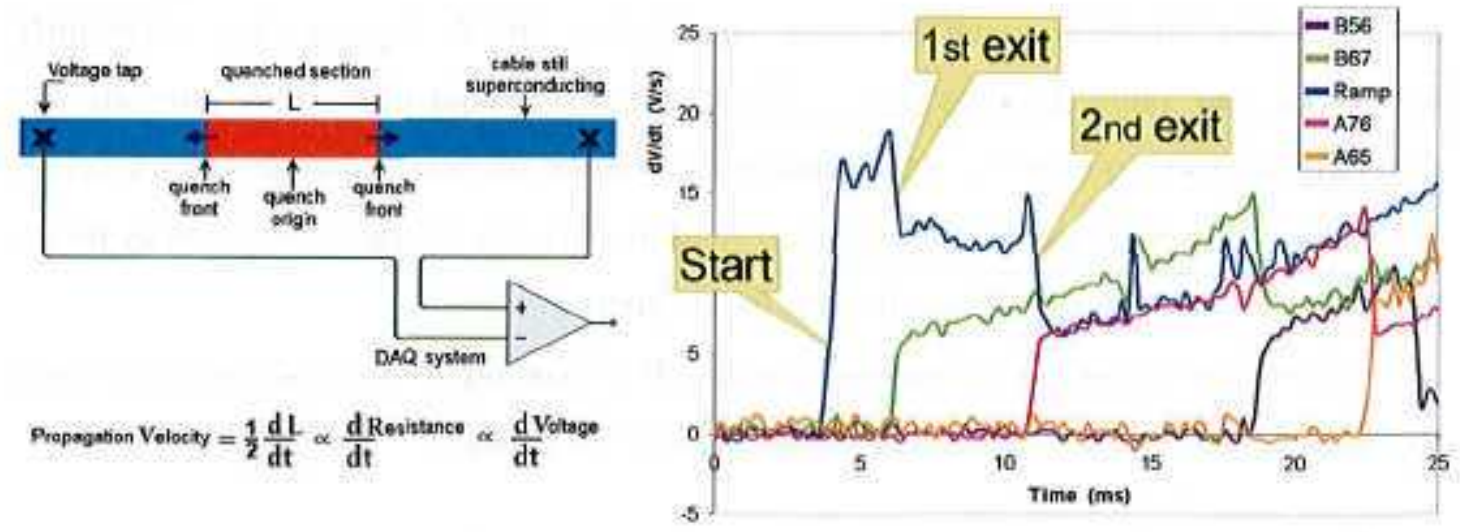

Fig 2. (left) Sketch of quench propagating along a superconducting cable. (right) Typical quench signals. The derivative of the voltage across the quenching cable is proportional to the quench propagation velocity times the number of quench fronts.

When a quench initiates, a step appears in the derivative of the voltage across the quenching sector $(\mathrm{dV} / \mathrm{dt})$. A non-zero derivative is maintained until the entire sector has quench and become normal conducting. Figure 2-right shows typical quench data collected during a quadrupole test [3]. Each trace corresponds to dV/dt for one particular sector from a series of neighboring cable sections. Notice how, when a quench-front passes a voltage tap, there is a negative step in $\mathrm{dV} / \mathrm{dt}$ for the sector the quench-front is leaving, and at the same time, an equivalent positive step in $\mathrm{dV} / \mathrm{dt}$ for the adjacent sector that the quench-front is entering. A negative step in $\mathrm{dV} / \mathrm{dt}$ can also occur when two quench-fronts traveling in opposite directions annihilate each other. This negative step will tend to be twice the size of a step due to a quench-front leaving a sector. 
The TOF technique allows to locate the position where a quench originated based on the time lapse between the start of the quench and the moment when each of the quenchfronts exit the quenching sector. The average quench propagation velocity for a sector can be obtained from the time required by the quench fronts to cover the entire sector. Corrections in quench propagation velocity based on local field values can be used to further reduce the error in locating the quench origin.

\section{Limitations and Alternatives to TOF Quench Location Technique}

Voltage taps (Vtap) are placed on a magnet with the purpose of locating the origin of quenches. This allows us to understand a magnet's behavior during a quench and identify its design and fabrication weakness. However, long acquisition time intervals are generally required to collect enough information on the quench dynamics, which delays the firing of the protection system. In high field magnets with large stored energy this is not appropriate due to possible damage to the magnet.

This section illustrates a limitation on the TOF technique, and presents two novel techniques used to extract additional information about a magnet's behavior.

\subsection{TOF Technique Limitations During TQS02 Analysis}

The Technology Quadrupole Shell (TQS) models are a key component of the US LARP program to develop $\mathrm{Nb}_{3} \mathrm{Sn}$ interaction-region quadrupoles for the luminosity upgrade of the LHC [4][5]. These magnets use $\cos 2 \theta$ coils in a shell-based support structure, as shown in Fig 3.

Two TQS models (TQS01, TQS02) were built and each one was tested in several configurations. TQS02 coils were equipped with $10 \mathrm{Vtaps}$ on the inner layer, and $6 \mathrm{Vtaps}$ on the outer layer. Fig 4-top shows a top view of a coil, while Fig 4-bottom shows a small section of the coil inner layer. Pads for Vtaps and the traces that route signals to the data acquisition system are circuit printed on a flexible insulator sheet, which is impregnated on the surface of the coil. 


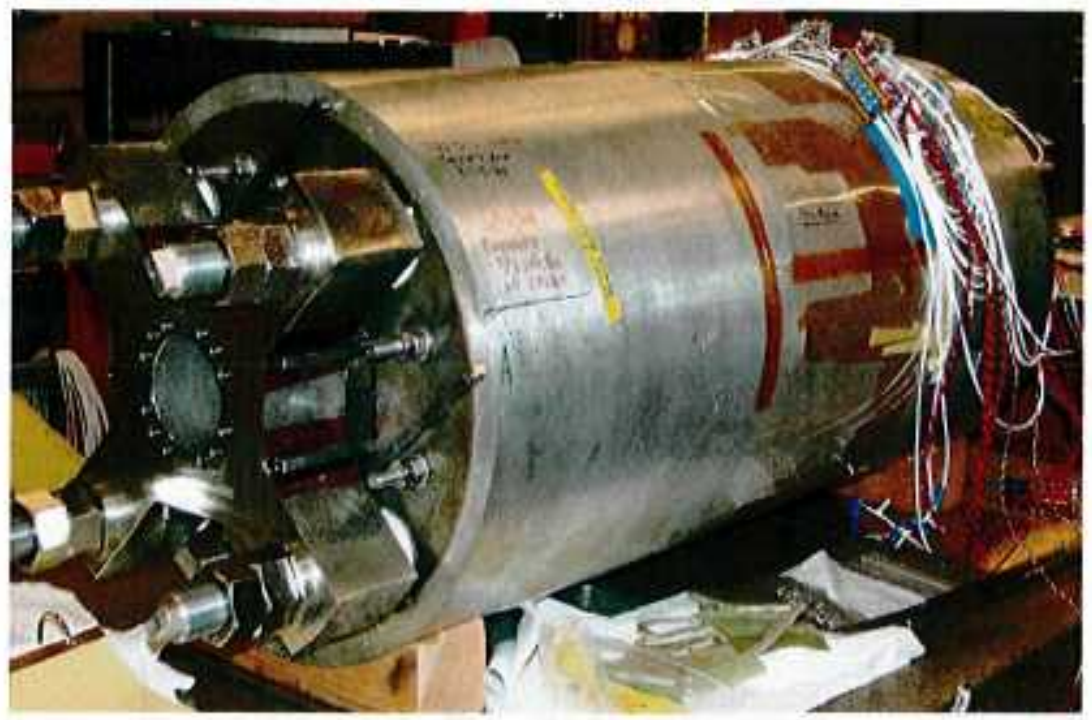

Fig 3. TQS02 quadrupole magnet.
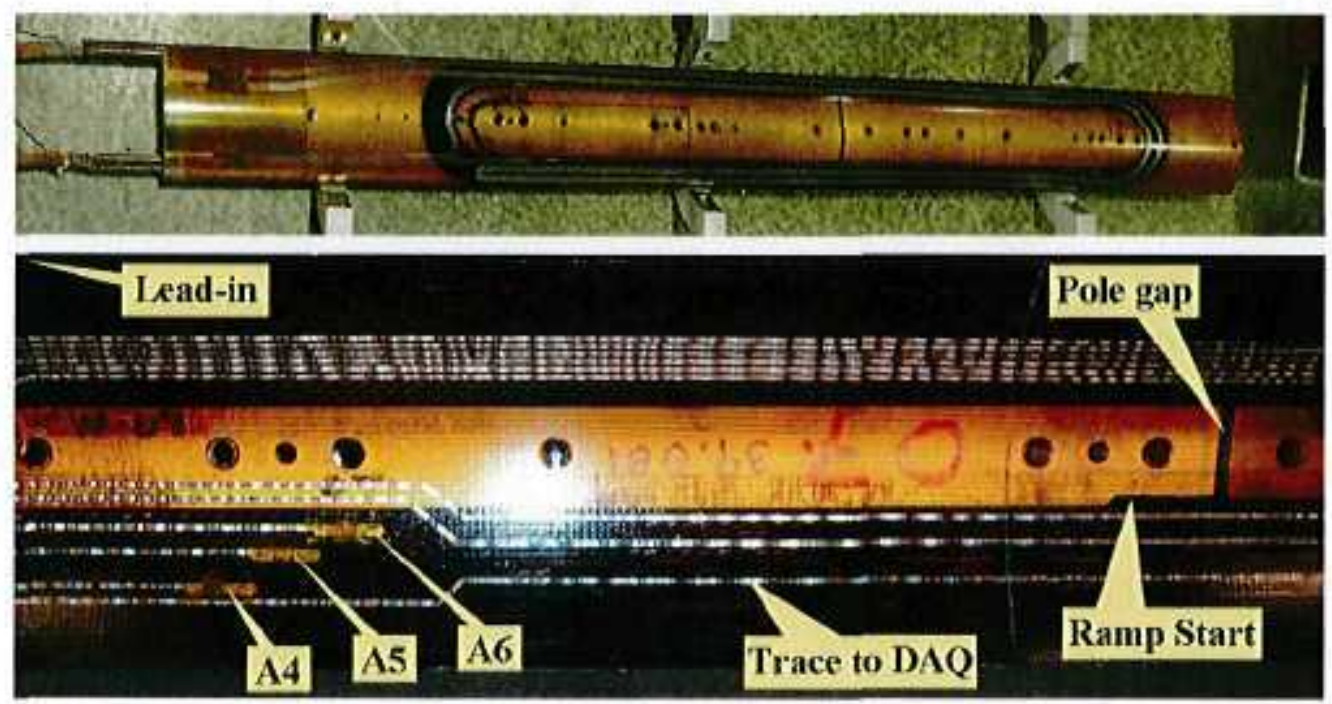

Fig 4. (top) One of four identical coils used on the TQS02 quadrupole magnet, viewed from the outer layer. (bottom) Detail of the inner layer, showing Vtaps A4, A5, A6 and circuit traces earrying signals to the data acquisition system. Pads for voltage taps and signal traces are impregnated on the coils surface.

Voltage tap locations were optimized to monitor the two pole turns, the turn around the wedge in the inner layer, two multi-turn sectors in the inner layer and one in the outer layer. Fig 5 shows an R- $\theta$ diagram of the coil: inner layer at the left, outer layer at the right. The blue vertical lines mark the locations of gaps between pole segments (also shown in Fig. 4). Vtaps A6/7 and A8/9 have two traces to the data acquisition system: one trace runs clock-wise around the pole, and the other one runs counter-clock-wise. 
In an ideal scenario, the data acquisition system records the exit (or annihilation) of all quench fronts from each voltage tap segment [6]. However, in the case of TQS02 this required a large delay on the energy extraction, which was not allowed due to concerns about coil damage from high temperature and local stress. The precautions taken to protect the magnet reduced the amount of useful data, and did not allowed us to make full time-of-flight calculations for any of the quenches. In this case, the time-of-flight analysis could only provide a range of possible quench origins.
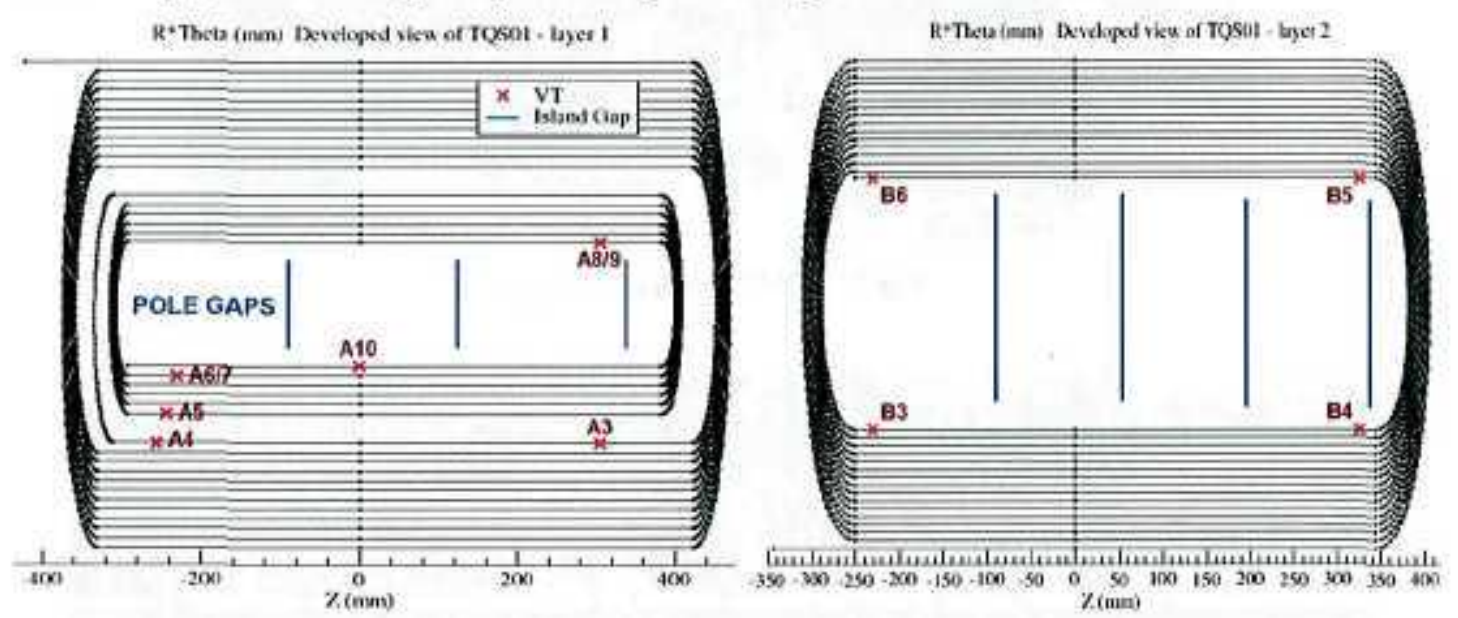

Fig 5. R- $\theta$ diagram of a TQSO2 coil. The drawing at the left/right side corresponds to the inner/outer layer. Vtaps are shown in red and pole gaps as blue vertical lines.

Identification of both transverse and longitudinal origin was attempted for each training quench. Transverse identification consists of locating the quenching turn of the coil winding, thus indicating possible correlations between quench origins and radial design features. A cross-sectional picture of a coil is shown in Fig 6-top, and its corresponding sketch in Fig 6-bottom. This diagram was used to mark the range of turns where each quench started as well as the quench sequence.

Since the quench-front exit times were not available in most cases, the longitudinal quench locations were constrained using the propagation velocities measured for a previous magnet with similar parameters [3] and the time-of-flight without exiting for each quench front. To mark the area identified as enclosing the quench origin, we used the R- $\theta$ diagram shown in Fig 5.

Fig 7 shows the training curve for magnet TQS02a tested at Fermilab [5]. The performance plateau (no increase in quench current over consecutive training ramps) at 
$4.4 \mathrm{~K}$ includes quench 21 through 26 (before $1.9 \mathrm{~K}$ training) and quench 48 through 54 (after $1.9 \mathrm{~K}$ training). The plateau at $1.9 \mathrm{~K}$ includes quench 34 through 45 .
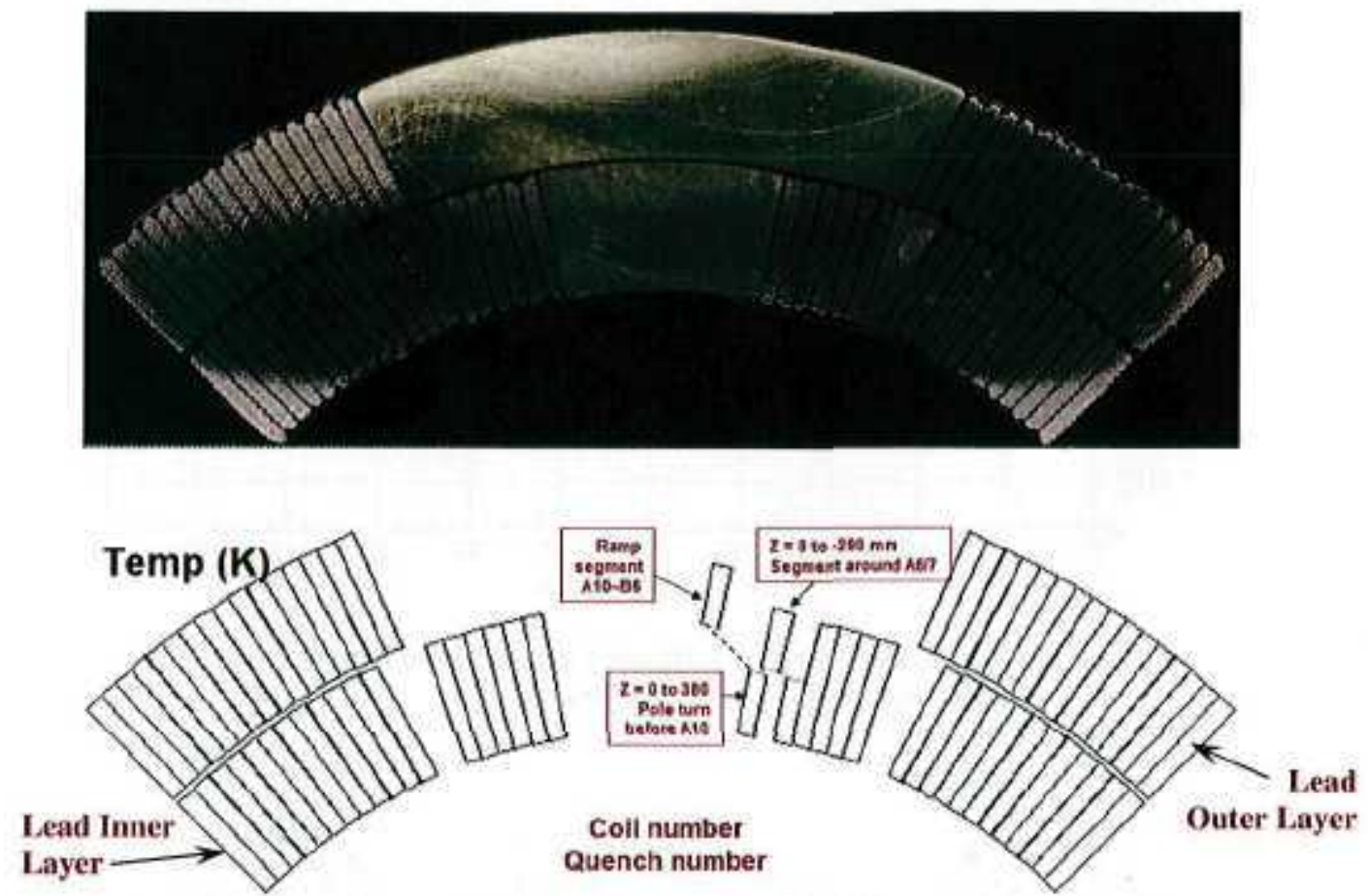

Fig 6. (Top) Picture of a TQS02 coil cross-section. (Bottom) Coil cross-section sketch as seen from the lead-end.

The transverse identification procedure described above was used to constrain the location of all plateau quenches. All plateau quenches originated in the same coil, and each had multiple and distributed quench origins starting in an interval between a fraction of a millisecond up to a few milliseconds from each other. Each plateau quench consisted of at least 4 independent sub-quenches.

Fig 8 illustrates the quench origins and sequence which applies to all plateau quenches at $4.4 \mathrm{~K}$ and $1.9 \mathrm{~K}$. The section of cable where the first quench origin is located is marked in orange. Notice the magnitude of the error resulting from the TOF technique for this particular case where no exits were recorded by the data acquisition system. We can only conclude that the first quench started somewhere in the outer layer outside the pole turn. This information is not enough to help understand the cause of this quench. 


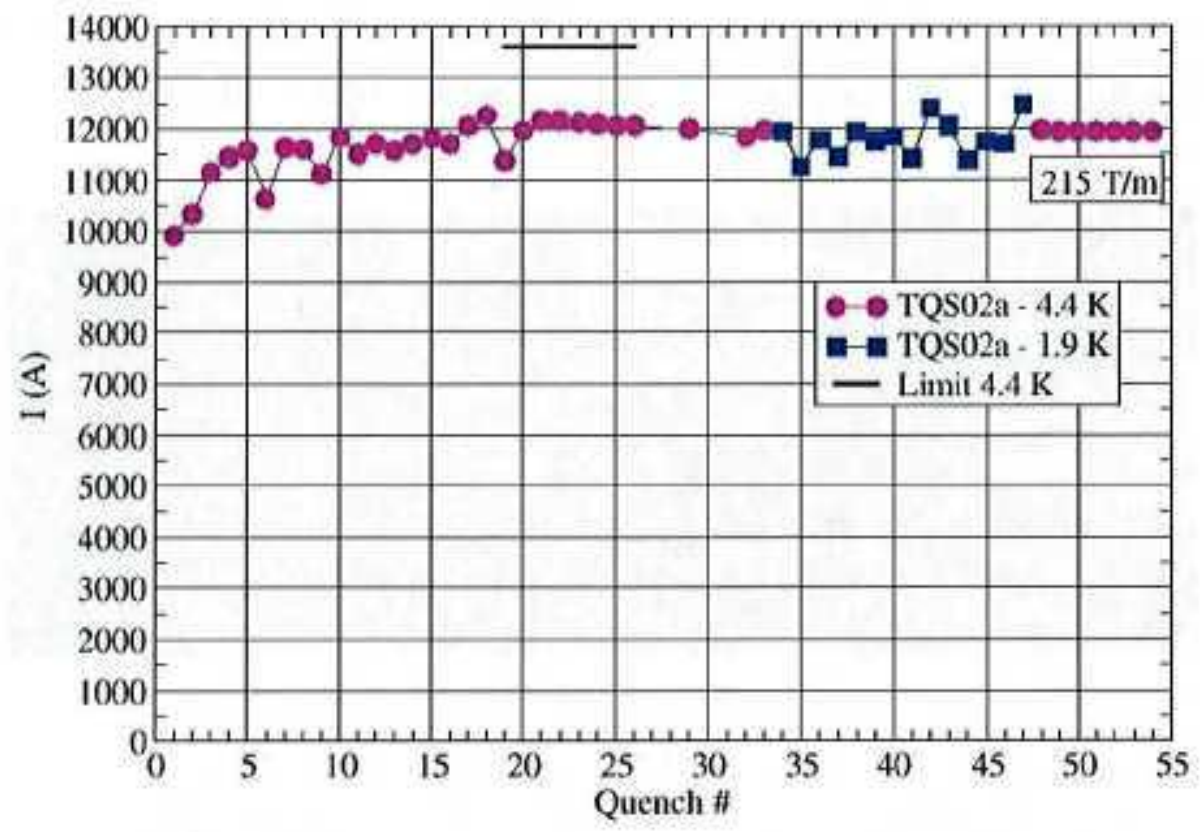

Fig 7. TQS02a training curve at $4.4 \mathrm{~K}$ and $1.9 \mathrm{~K}$. Expected current limit at $1.9 \mathrm{~K}$ is about $8 \%$ higher than the expected limit at $4.4 \mathrm{~K}$
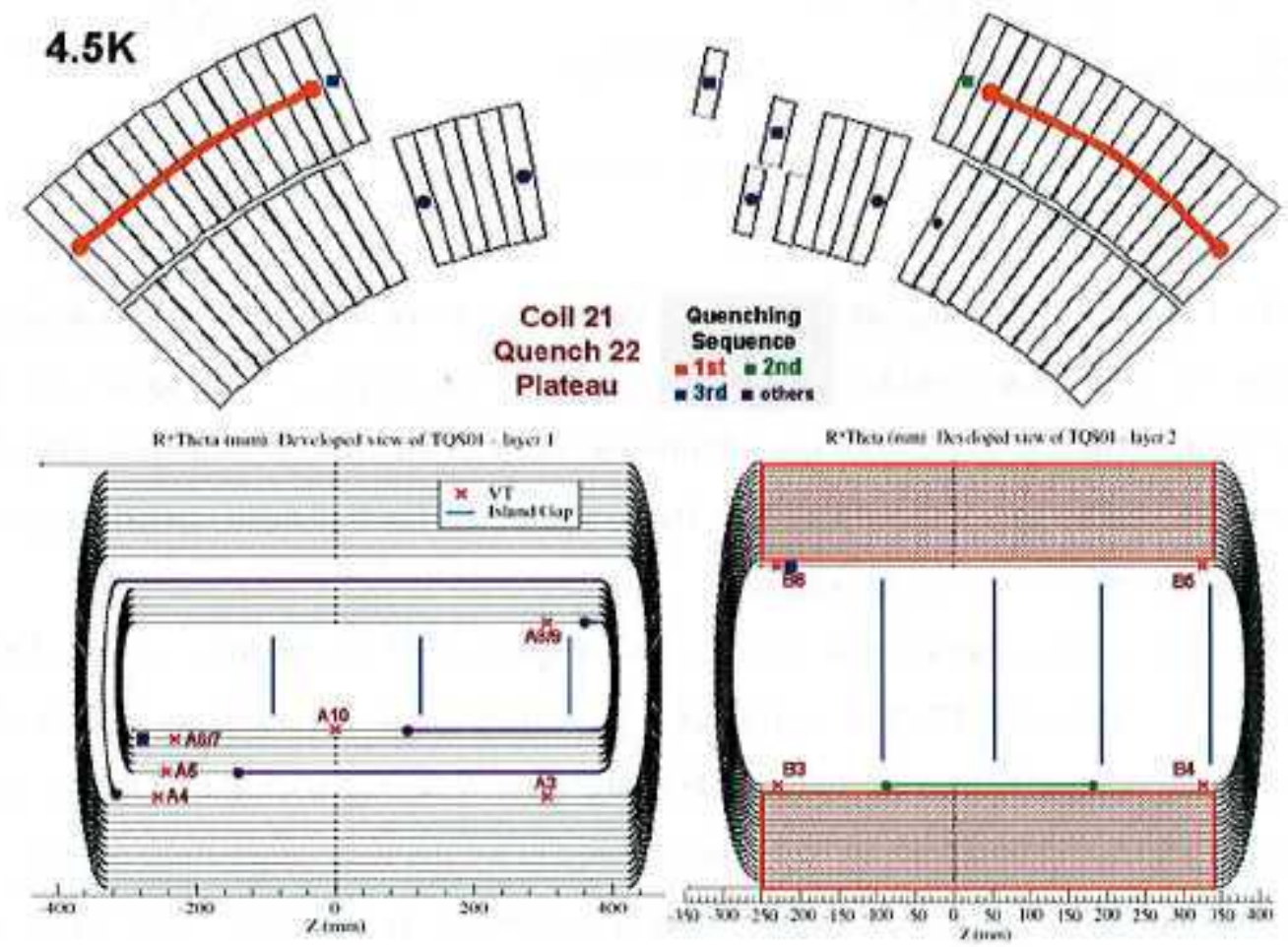

Fig 8. Color coded quench sequence for plateau quenches at $4.4 \mathrm{~K}$ and $1.9 \mathrm{~K}$ 
The second quench origin is located in the straight sector at the lead side of the pole turn in the outer layer, marked with green in Fig 8. In this case the location error is smaller, but still too large to correlate with mechanical or magnetic design features. A third quench starts close to voltage tap B6 placed in the outer layer at the end of the ramp. Multiple subsequent quenches occur in the inner layer.

The above analysis leaves several questions open. In particular we would like to understand (1) whether the quench origins at $4.4 \mathrm{~K}$ and $1.9 \mathrm{~K}$ are all the same or not; (2) the nature of the variability on quench current at $1.9 \mathrm{~K}$, which is not observed at $4.4 \mathrm{~K}$. The following section addresses this problem with a novel analysis.

\subsection{Quench Velocity Profile Technique}

As a quench front propagates along a cable, its instantaneous propagation velocity is correlated to the local critical-current margin at the location of the advancing quenchfront. This small variability on local critical-current margin is due to inhomogeneities on a cable's local structure. Thus, the local quench propagation velocity profile is unique to each section of a cable. Also, the time derivative of the voltage across a quenching sector (dV/dt) is proportional to the instantaneous quench propagation velocity. Thus, $\mathrm{dV} / \mathrm{dt}$ provides a detailed characterization of the section of cable where a quench is propagating [7]. This characterization allows determining whether or not two different quenches originated at the same location, or if several quench origins exist. Following this approach, the $\mathrm{dV} / \mathrm{dt}$ profiles for the first and second quenches in each plateau were compared. The first quench refers to the one in the multi-turn sector marked in orange in Fig 8 , and the second quench refers to the quench in the straight sector marked in green.

A first comparison was made among the set of plateau quenches at $4.4 \mathrm{~K}$ before training at $1.9 \mathrm{~K}$. A second comparison included all quenches at $4.4 \mathrm{~K}$ after training at $1.9 \mathrm{~K}$. A third comparison was made between the quench velocity profile for quenches at $4.4 \mathrm{~K}$ before training at $1.9 \mathrm{~K}$, and the profile at $4.4 \mathrm{~K}$ after training at $1.9 \mathrm{~K}$. Finally, a fourth comparison was made among quenches at $1.9 \mathrm{~K}$.

Figures 9 and 10 show $\mathrm{dV} / \mathrm{dt}$ for the multi-turn sector and the straight sector respectively, for plateau quenches $21,22,23,24$ and 25 at $4.4 \mathrm{~K}$ before going to $1.9 \mathrm{~K}$. Notice how the signals collected from the same sector in each of these different training 
quenches are identical, indicating that they are all propagating through the same cable segment. We can therefore conclude that all plateau quenches at $4.4 \mathrm{~K}$ before going to $1.9 \mathrm{~K}$ have a common quench origin.

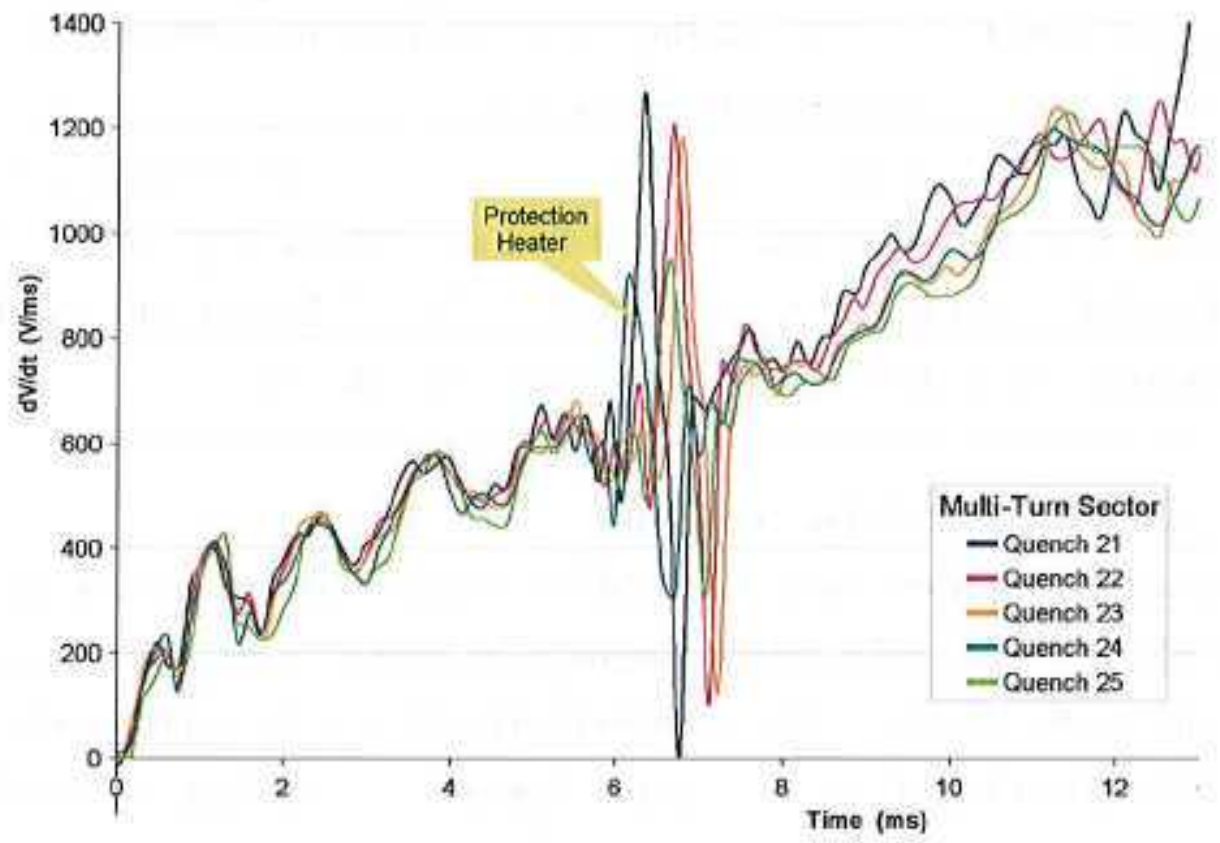

Fig 9. Multi-turn sector signals from plateau quenches at $4.4 \mathrm{~K}$ before training at $1.9 \mathrm{~K}$.

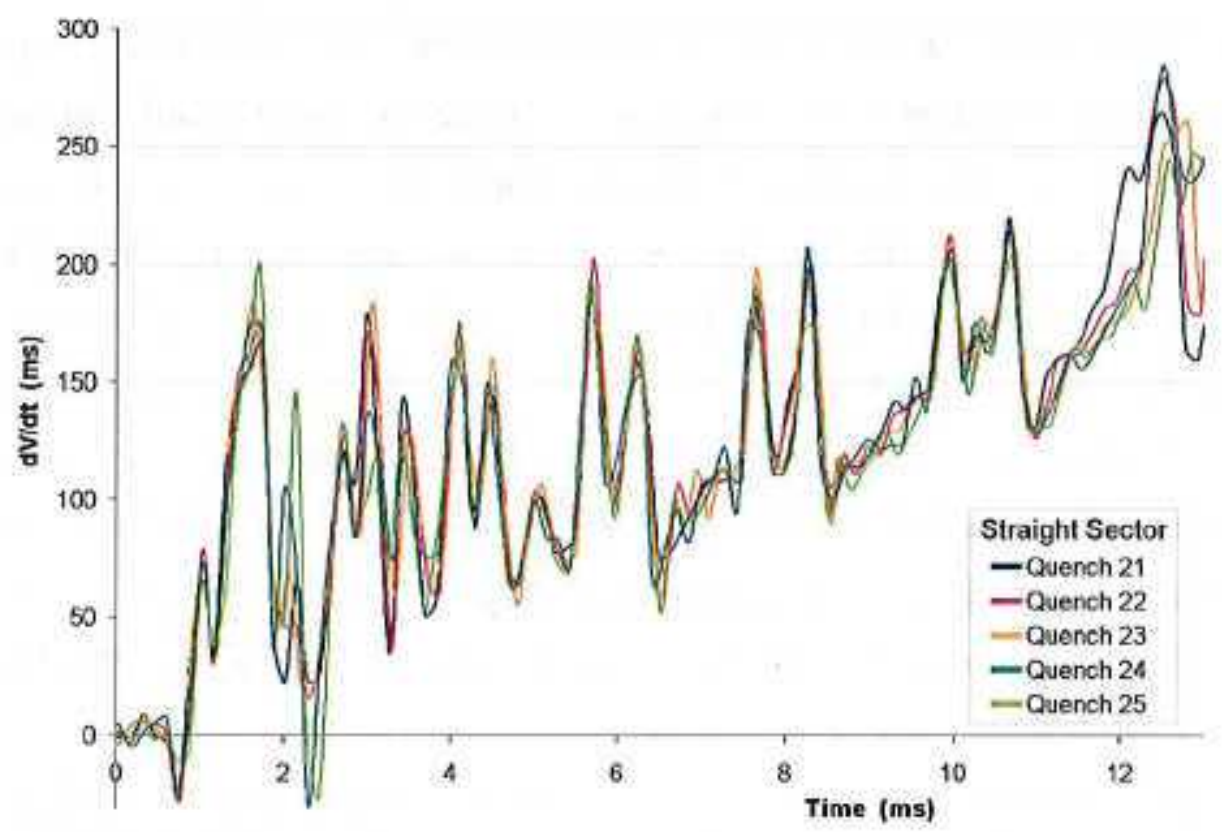

Fig 10. Straight sector signals from plateau quenches at $4.4 \mathrm{~K}$ before training at $1.9 \mathrm{~K}$. 
Figures 11 and 12 show $\mathrm{dV} / \mathrm{dt}$ signals for the multi-turn sector and the straight sector respectively, for quenches $49,50,51,52,53$ and 54 , corresponding to the training plateau at $4.4 \mathrm{~K}$ after training at $1.9 \mathrm{~K}$. An identical quench velocity profile indicates a common origin for all quenches.

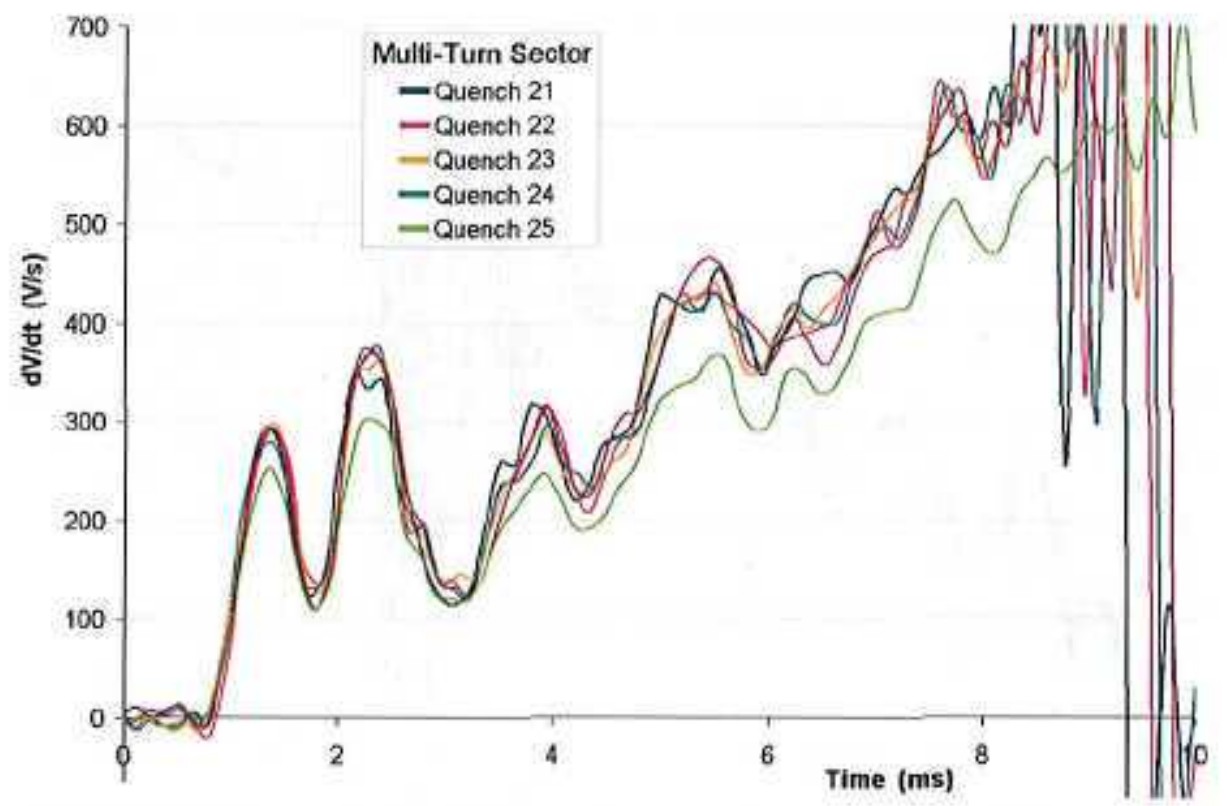

Fig 11. Multi-turn sector signals from plateau quenches at $4.4 \mathrm{~K}$ after training at $1.9 \mathrm{~K}$.

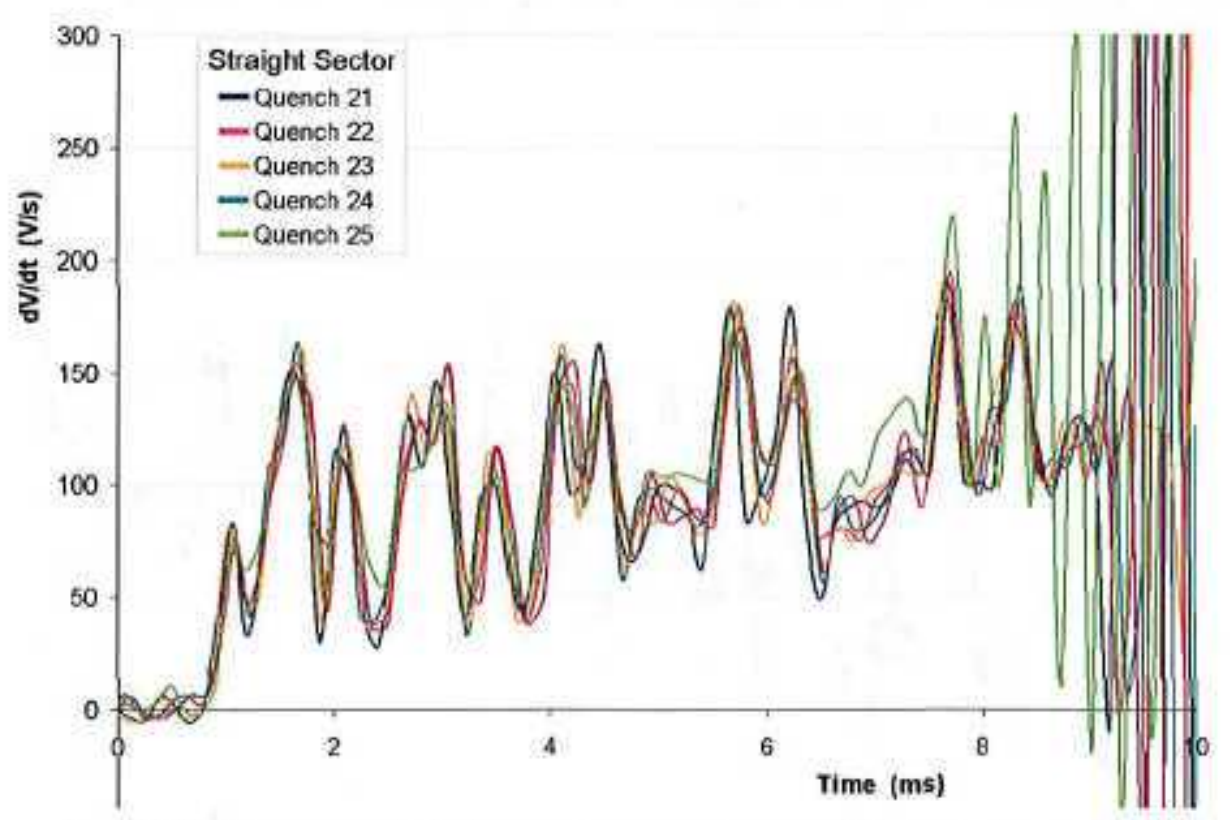

Fig 12. Straight sector signals from plateau quenches at $4.4 \mathrm{~K}$ after training at $1.9 \mathrm{~K}$. 
Fig 14 compares straight sector signals collected from plateau quenches at $4.4 \mathrm{~K}$ before going to $1.9 \mathrm{~K}$ (blue), with signals from the same sector but from plateau quenches at $4.4 \mathrm{~K}$ after going to $1.9 \mathrm{~K}$ (brown). After correcting for trigger time delay, we can conclude that the origin of the quench in the straight sector is the same before and after the plateau at $1.9 \mathrm{~K}$.

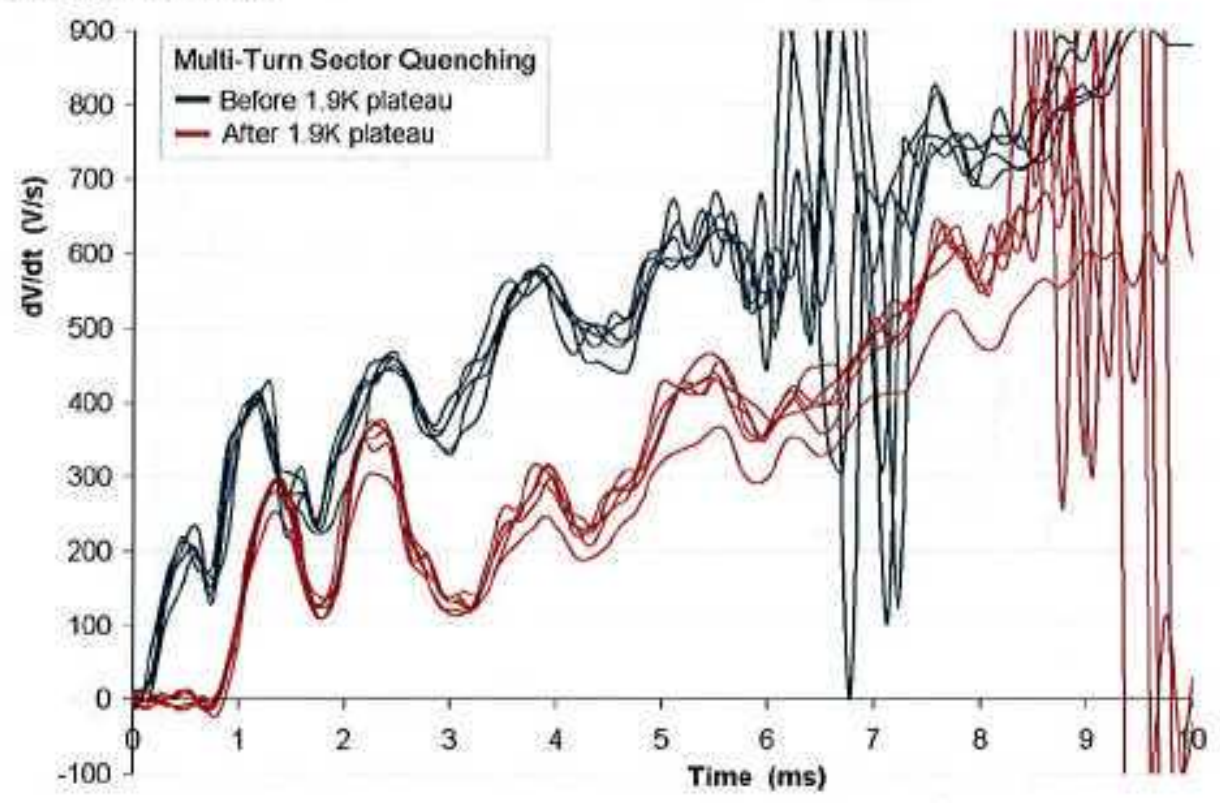

Fig 13. Multi-turn sector quench signals at $4.2 \mathrm{~K}$ before (blue) and after (brown) $1.9 \mathrm{~K}$ training.

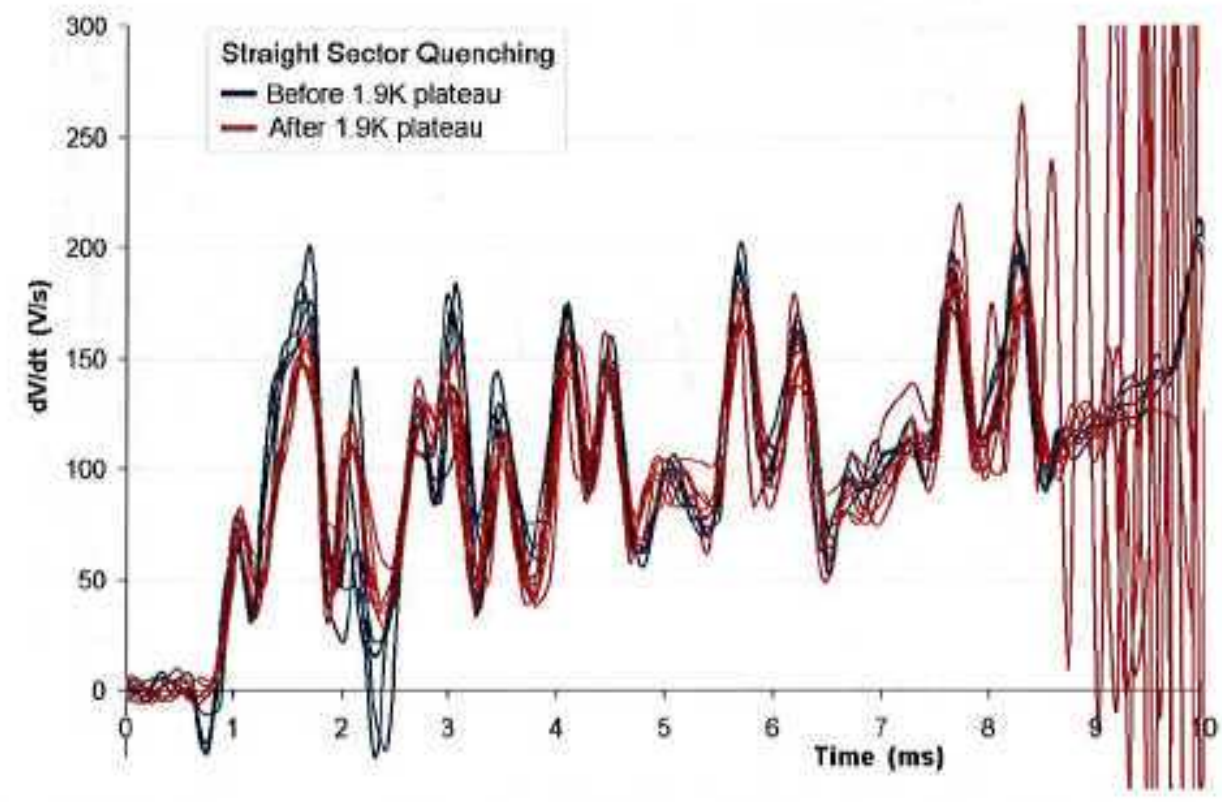

Fig 14. Straight sector quench signals at $4.4 \mathrm{~K}$ before (blue) and after (brown) $1.9 \mathrm{~K}$ training. 
Fig 13 compares multi-turn sector signals collected from plateau quenches before $1.9 \mathrm{~K}$ training (blue), with signals from the same sector after $1.9 \mathrm{~K}$ training (brown). Both groups are plotted using the same trigger delay used on the straight sector (Fig 14). In this case, lower $\mathrm{dV} / \mathrm{dt}$ values are recorded after $1.9 \mathrm{~K}$ training. In addition, there is a $0.7 \mathrm{~ms}$ delay in the quench start after $1.9 \mathrm{~K}$ training. This data indicates that the first quench origin which was present before $1.9 \mathrm{~K}$ training was no longer there after $1.9 \mathrm{~K}$ training. We can also conclude that this initial quench front had a mechanical origin, since it disappeared as a consequence of the training process.

Figures 15 and 16 show $\mathrm{dV} / \mathrm{dt}$ for the multi-turn sector and the straight sector for quenches 34 to 46 , corresponding to the $1.9 \mathrm{~K}$ plateau. These signals have different shape and do not overlay by adding a constant delay or correcting for small differences on quench propagation velocity. However, four groups of identical signals can be identified, indicating that four different types of quenches characterized this plateau. Within each group, the quenches appear identical for the straight and the multi-turn sectors, indicating a common quench origin.

In order to better understand the quench current variability of the $1.9 \mathrm{~K}$ plateau, which was not present at $4.4 \mathrm{~K}$, the data points in the training curve at $1.9 \mathrm{~K}$ were identified according to the four different quench origins described above.

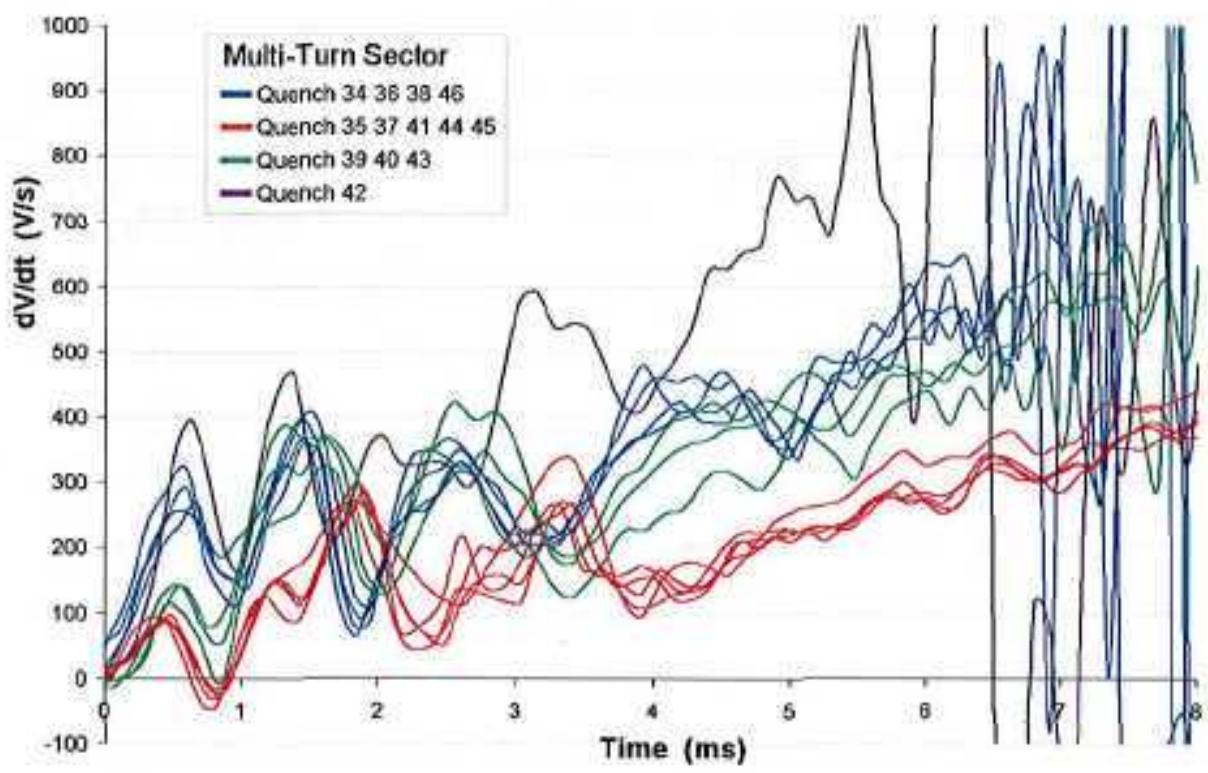

Fig 15. Multi-turn sector signals from plateau quenches at 1.9K. Four different quench velocity profiles are indicating with different colors. 


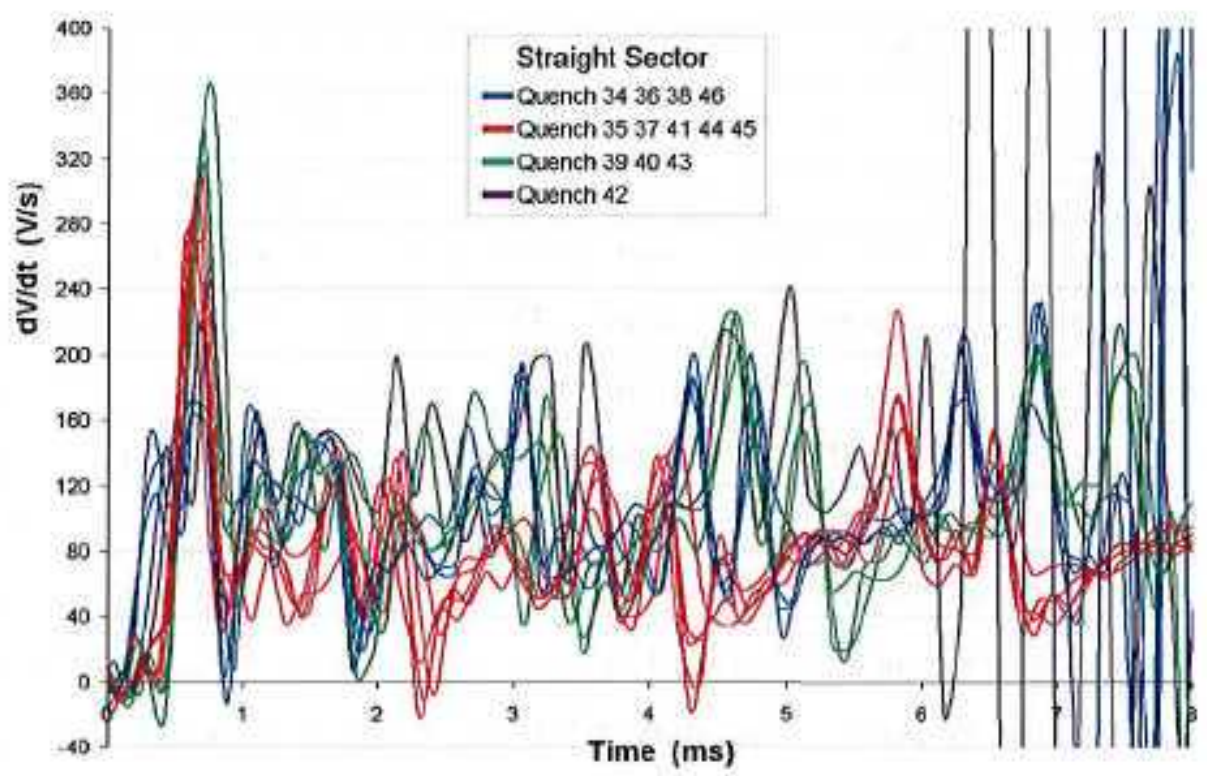

Fig 16. Straight sector during plateau quenches at $1.9 \mathrm{~K}$. Four different quench velocity profiles are indicated with different colors.

Fig 17-left shows a detail of the $1.9 \mathrm{~K}$ platcau, using a unique color to mark quenches from each of the 4 quench origins found with the quench velocity profile technique. This plot shows a correlation between the quench origin and the quench current, suggesting that the quench current variability observed at $1.9 \mathrm{~K}$ can be explained by a change in quench origin that does not occur for the plateau at $4.4 \mathrm{~K}$.

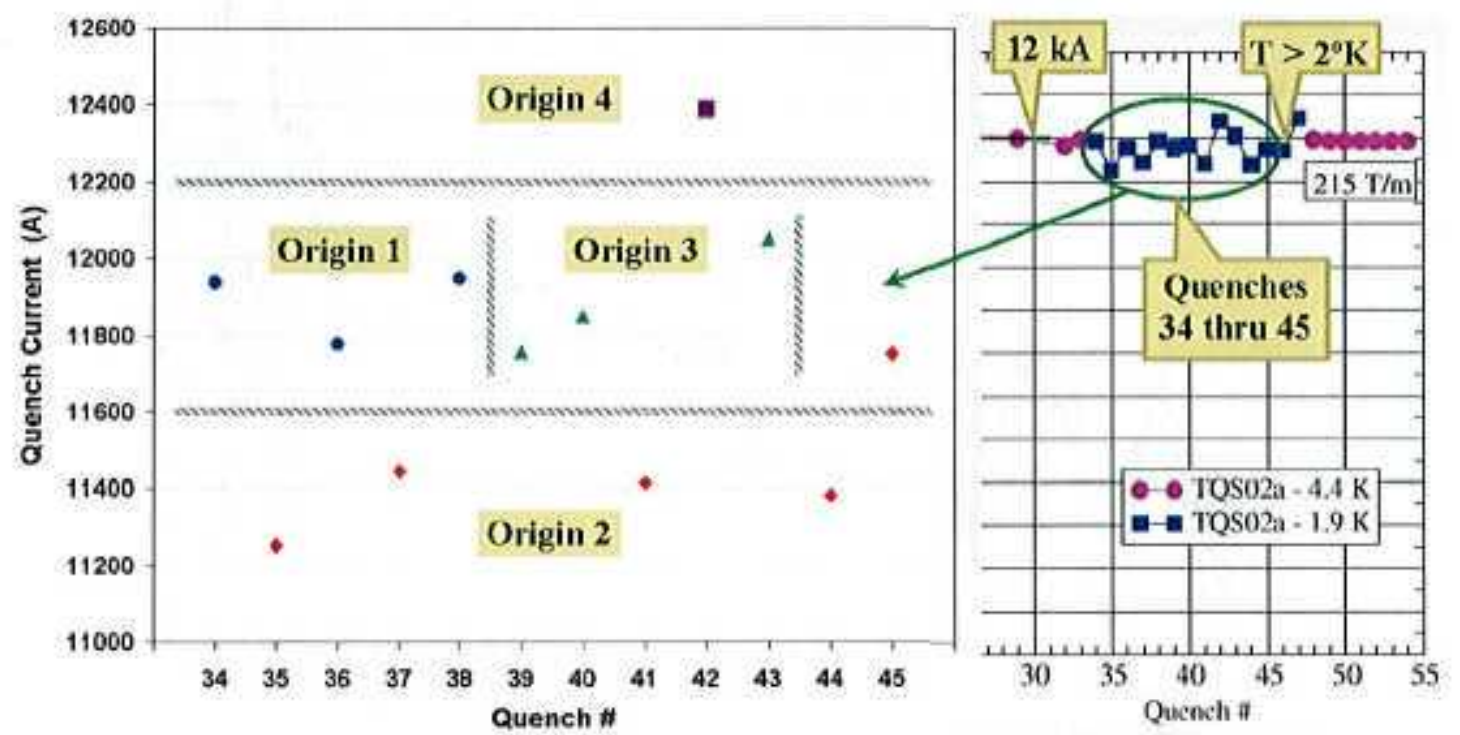

Fig 17. Quenching current color coded according to the 4 different quench origins found at $1.9 \mathrm{~K}$ 
In conclusion, by using the quench velocity profile technique we could extract additional information not provided by the TOF quench location technique used in section 3.1. Based on this analysis, we can make the following conclusions:

(1) All $4.4 \mathrm{~K}$ plateau quenches before going to $1.9 \mathrm{~K}$ share the same origin, sequence and propagation mechanism.

(2) All $4.4 \mathrm{~K}$ plateau quenches after going to $1.9 \mathrm{~K}$ share the same origin, sequence and propagation mechanism.

(3) Training of the earliest quench origin at $4.4 \mathrm{~K}$ occurred during testing at $1.9 \mathrm{~K}$. However, the quench origin for the quench at $4.4 \mathrm{~K}$ starting in the straight sector did not change after testing at $1.9 \mathrm{~K}$

(4) $1.9 \mathrm{~K}$ plateau quenches do not share a common origin for either the multi-turn or the straight sector. There are at least 4 different quench origins at $1.9 \mathrm{~K}$.

(5) At $1.9 \mathrm{~K}$ a correlation between quench current and quench origin exists.

\subsection{Voltage Tap Data Limitations During HD2b Analysis}

HD2 is part of a series of high field dipoles being developed by the Superconducting Magnet Program at Lawrence Berkeley National Laboratory. These magnets are built using block-type coils in a shell based support structure as shown in Figure 18 [6][8].

During the test of a dipole called HD2b, after performing 13 training quenches, a failure in the energy extraction system caused a condition potentially harmful to the magnet. Data collected during the failure indicated that the current through the magnet remained almost unchanged after magnet energy extraction, which means that a larger than-usual energy fraction was dissipated inside the magnet.

A change in the magnet performance was also observed in subsequent training ramps, as shown by the training plot in Fig 19. The ramping profile up to quench 14 was $50 \mathrm{~A} / \mathrm{s}$ until reaching $11 \mathrm{kA}$, and $20 \mathrm{~A} / \mathrm{s}$ thereafter. Following the low performance at quench 14 , less aggressive ramping profiles were attempted until a quench current similar to the one obtained for quench 13 was reached at quench 21 . The ramping profile for quench 21 was $50 \mathrm{~A} / \mathrm{s}$ up to $5 \mathrm{kA}$, then $20 \mathrm{~A} / \mathrm{s}$ up to $11 \mathrm{kA}$ and $10 \mathrm{~A} / \mathrm{s}$ thereafter. 


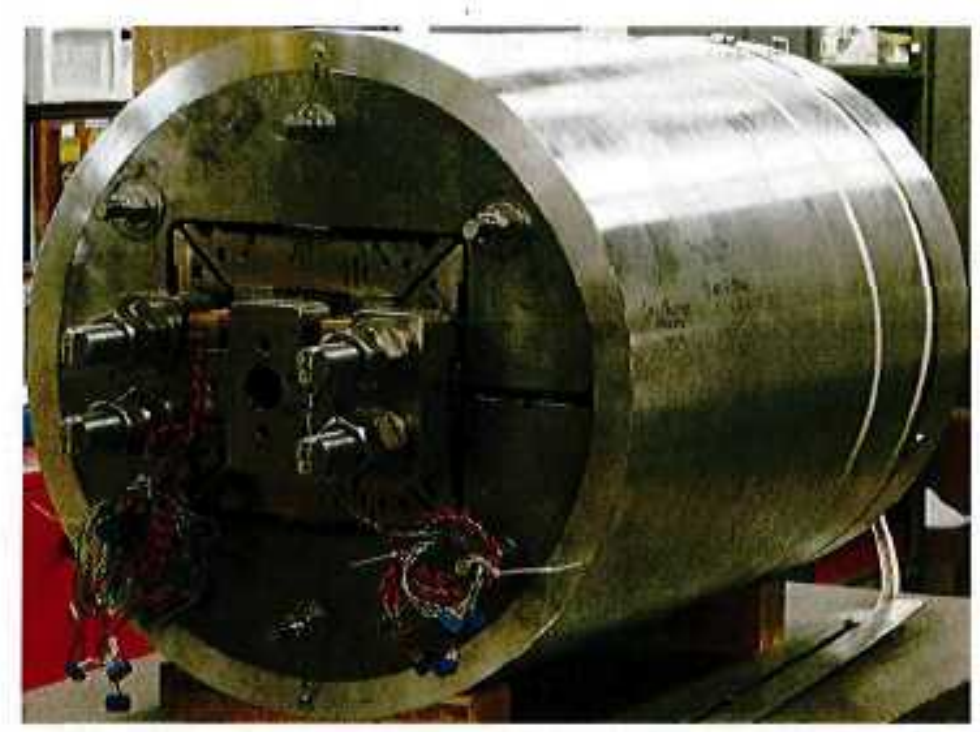

Fig 18. HD2 high field dipole.

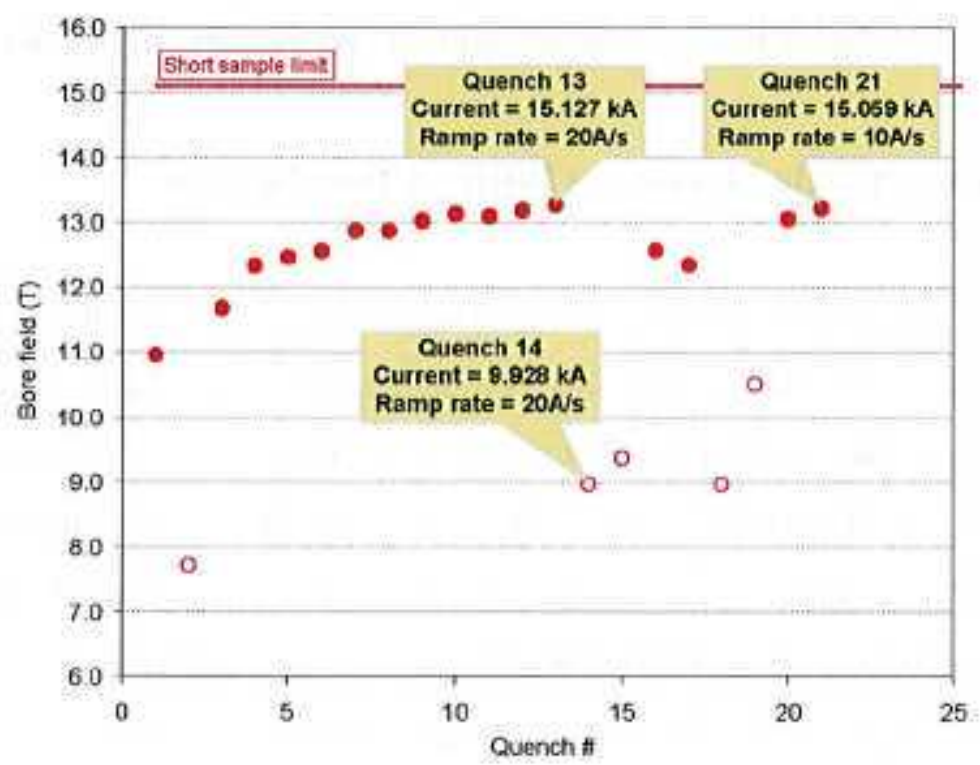

Fig 19. HD2 training curve.

The TOF quench location technique was not helpful in better understanding the performance change after quench 13. The following section will use data from voltage taps and a technique based on analyzing transient flux imbalances, to better characterize this performance change. 


\subsection{Voltage Tap Data From Transient Imbalances to Diagnose Cable Integrity}

Two types of fast transient events had been observed during current ramping of high field $\mathrm{Nb}_{3} \mathrm{Sn}$ magnets: Flux-Jumps and Slip-Sticks. Flux-Jumps (FJ) are believed to be caused by the sudden de-pinning and flow of flux lines in the $\mathrm{Nb}_{3} \mathrm{Sn}$ superconducting filaments, producing a change in magnetic field and inducing a voltage signal across the terminals of the magnet [9][10][11]. Slip-Sticks (SS) are mechanical vibrations triggered when Lorentz forces cause sections of the magnet structure to re-arrange and release energy in the form of damped oscillations [10][11]. FJS and SSs occur spontaneously along the magnet while the current is being ramped. Their duration ranges from a fraction of a millisecond to tens of milliseconds. These events are often responsible for initiating a magnet quench.

A change in FJ shape, size or statistical distribution indicates a change in the cable properties. Also, an asymmetry on FJ distribution between presumably identical coils under similar conditions would reflect a difference in current-temperature margin between the coils. Thus, FJ distribution changes can be used to diagnose conductor or coil fabrication faults.

The change in performance due to the excess energy deposited in the HD2b dipole after failure of the energy extraction system, as described in section 3.3 , indicated that a change in the conductor properties had occurred [12]. To verify this possibility, a statistical study of FJs collected before and after the failure was performed.

The chosen statistical variable was the net integrated flux imbalance per. FJ. This patameter is calculated by finding the difference in $\mathrm{d} \Phi / \mathrm{dt}$ between the two coils in the dipole, and then integrating it over the time span of the event. To measure $\mathrm{d} \Phi / \mathrm{dt}$, our data acquisition system was programmed to record the derivative of the voltage induced at the terminals of each coil, which corresponds to the second derivative of the net magnetic flux linking the coils.

During magnet ramping hundreds of events were collected. To process them, a software tool was developed to select flux-jump events based on the difference in frequency components between flux-jumps and stick slips. This tool also identifies the boundaries of each flux jump falling within the $100 \mathrm{~ms}$ time-window recorded by the data 
acquisition system. Once the event and its time boundaries have been identified, the program generates a first integral to obtain $\mathrm{d} \Phi / \mathrm{dt}$, and a second integral to generate $\Phi(\mathrm{t})$. It should be noted that this $\Phi(t)$ is not the total flux generated by the flux jump, but only a fraction of it. Most of the flux lines associated with an event return within the same coil where the event originated, and only the flux lines that close outside the coil induce a voltage at the terminals of it.

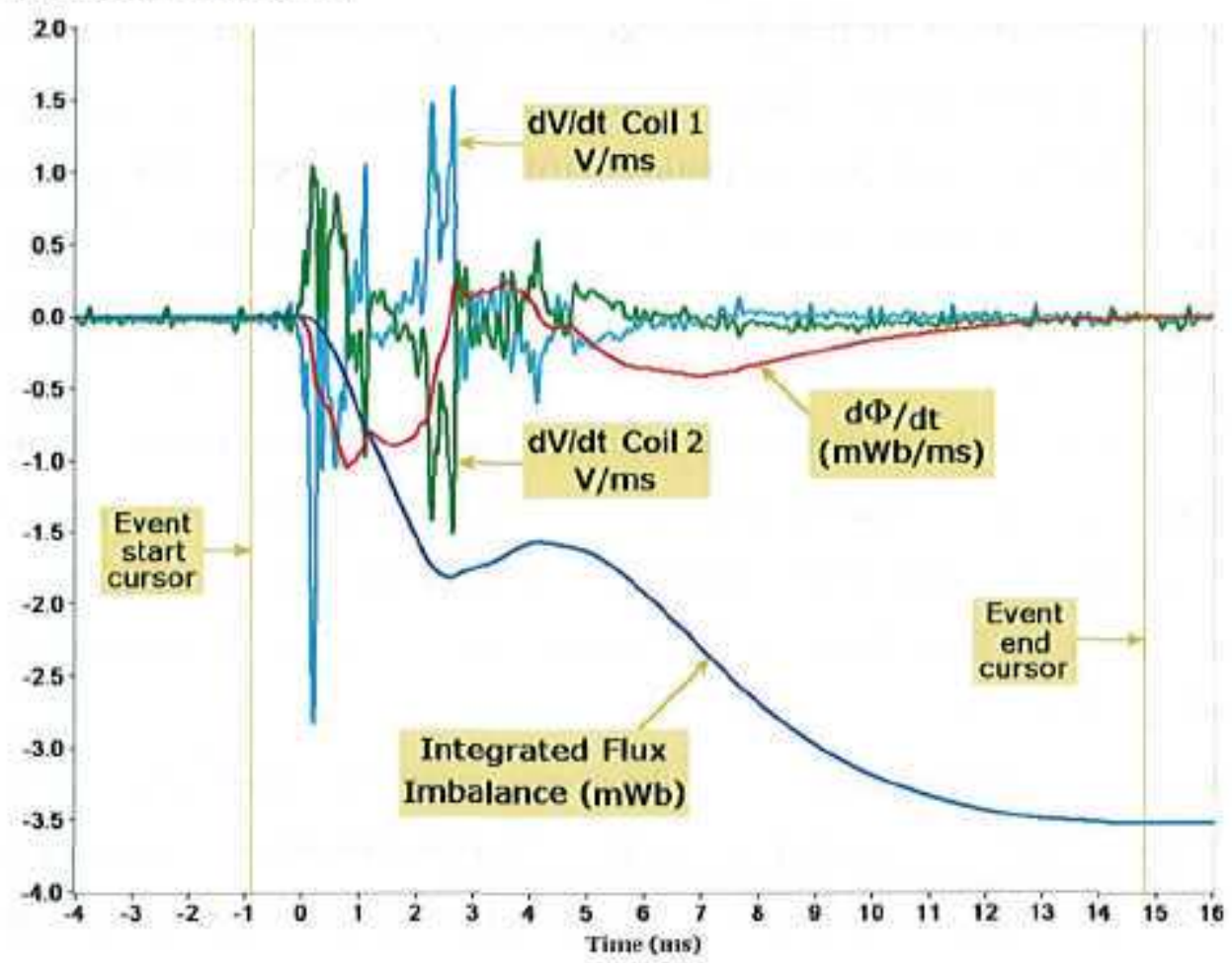

Fig 20. Flux-Jump coil signals, including traces outputted by analysis software.

Figure 20 shows a composite flux jump event, including $d \Phi / d t$ and $\Phi(t)$ calculated by the analysis software. The traces labeled as Coill and Coil2 are the raw signals collected in units of $\mathrm{V} / \mathrm{ms}$, corresponding to the derivative of the voltage at each coil terminals. The trace labeled as $\mathrm{d} \Phi / \mathrm{dt}$ is the calculated derivative of the flux imbalance between coils (in units of milliWebers per millisecond). The signal polarity indicates that this FJ started in Coil2 at time zero (DAQ trigger time), and after $\sim 2.5 \mathrm{~ms}$ a second FJ was triggered in Coill. However, after $\sim 4 \mathrm{~ms}$ the FJ in Coill starts to decay, and at $7 \mathrm{~ms}$ it has almost extinguished. The tail in $\mathrm{d} \Phi / \mathrm{dt}$ signal after $8 \mathrm{~ms}$ is the decay of the FJ that originally started in Coil2. $\Phi(t)$ is the trace labeled as Integrated Flux Imbalance, which is the 
imbalance in flux enclosed by each coil.

The event shown in Fig 20 is the result of multiple flux-jumping as it was mentioned above; however, most events collected are single FJs that do not trigger further depinning in other parts of the magnet.

The net integrated flux imbalance per FJ, which is the chosen statistical variable to study, is the value of the integrated flux imbalance at the end of an event. This value was calculated for each FJ over two training ramps before the extraction system failure and two training ramps after the extraction system failure. The chosen ramps share the same ramp rate, trigger threshold and include events up to the same current level. The resulting distributions are shown in Fig 21.

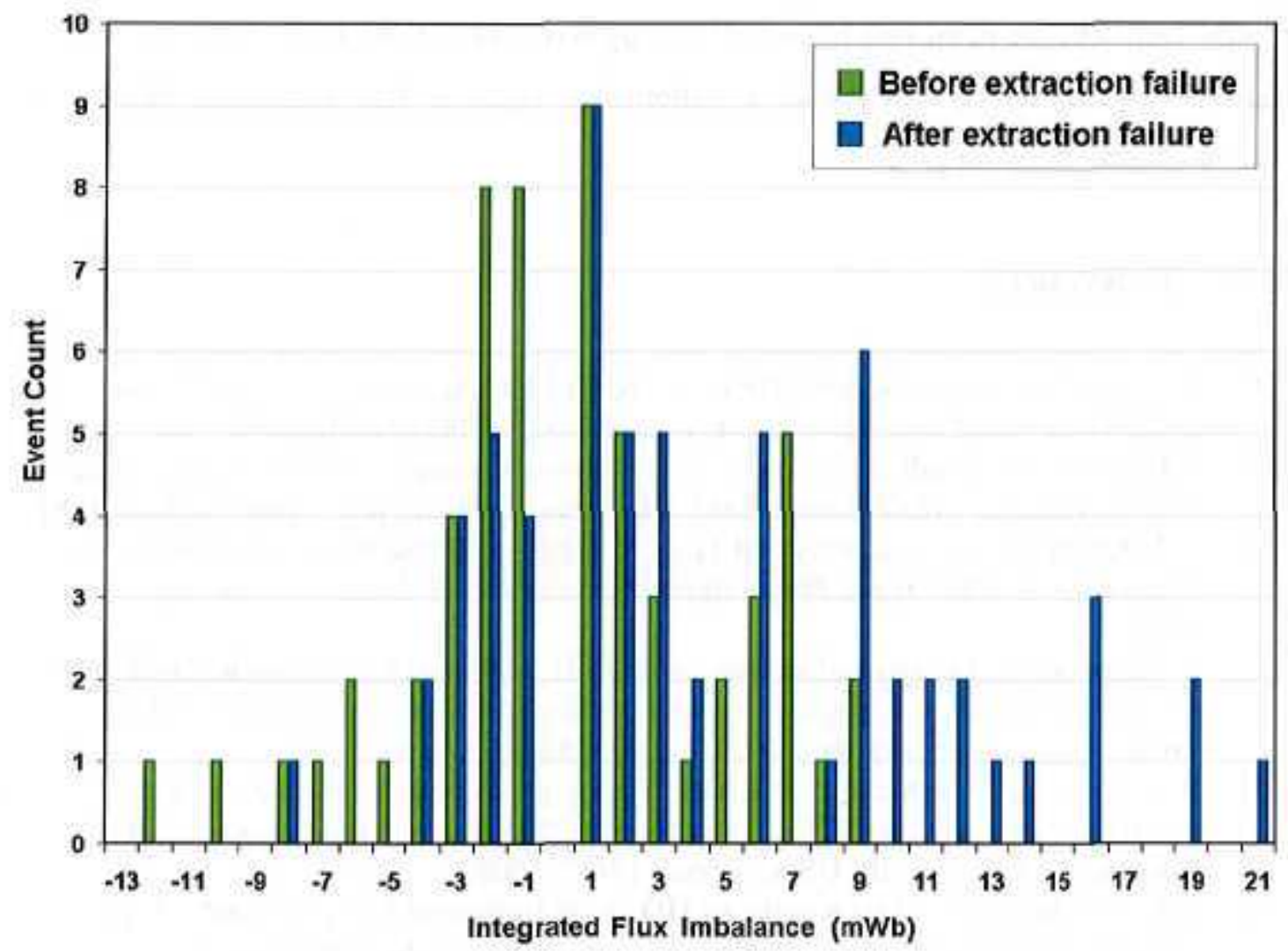

Fig 21. Flux-Jump signal after processing by the analysis software.

The sign of the integrated flux imbalance in the histogram in Fig 21 is such that a FJ that occurred mostly in Coill has a positive sign, and a FJ that occurred mostly in Coil2 has a negative sign. Notice how the number and magnitude of the FJs in Coill increased with respect to Coil2. We can then conclude that the magnet-energy extraction failure that 
occurred during HD2 testing caused a change in the current-temperature margin of the cable in Coill. This change in current-temperature margin can be considered the cause for the performance change observed in subsequent training ramps.

\section{Conclusions}

We have presented two innovative techniques to analyze voltage tap signals and gain new insights on magnet performance issues. In the first case, we were able to determine whether a distributed or a localized problem was limiting the performance of a focusing quadrupole magnet by comparing quench velocity profiles. In the second case we diagnosed a change in current-temperature margin of a high field dipole by using voltage tap data to find changes in statistical patterns of transient flux fluctuations that occur during current ramping.

\section{References}

[I] S.A. Gourlay, et al., "Magnet R\&D for the IS LHC Accelerator Research Program", IEEE Trans. Appl. Supercond, vol. 16, no. 2, June 2006, pp. 324-327.

[2] J. Lizarazo, et al, "Measurement of Fast Voltage Transients in High-Performance Nb3Sn Magnets", IEEE Trans. Appl. Supercond., vol. 18, no. 2, June 2008, p. 1581.

[3] P. Ferracin, et al., "Assembly and Tests of SQ02, a Nb3Sn Racetrack Quadrupole Magnet for LARP", IEEE Trans. Appl. Supercond, vol. 17, no. 2, June 2007, p. 1019.

[4] S. Caspi et al., "Design and analysis of TQS01, a $90 \mathrm{~mm}$ Nb3Sn model quadrupole for the LHC luminosity upgrade based on a key and bladder assembly", IEEE Trans. Appl. Supercond., vol. 16, no. 2, pp. 358-361, June 2006.

[5] S. Caspi, et al., "Test results of LARP $\mathrm{Nb}_{3} \mathrm{Sn}$ quadrupole magnets using a shellbased support structure (TQS)", presented at 2008 Applied Superconductivity Conference, Chicago, IL, USA, August 17-22, 2008.

[6] A.F. Lietzke, et al., "Test Results of HDIb, an Upgraded 16 Tesla Nb3Sn Dipole Magnet", IEEE Trans. Appl. Supercond., vol. 15, no. 2, June 2005, p. 1123.

[7] A.F. Lietzke, J. Lizarazo. "TQS01 \& TQS02 Plateau Quenching", LARP Document 651. LARP collaboration meeting \#9 at SLAC. Oct 17-19/2007.

[8] P. Ferracin, et al., "Development of the $15 \mathrm{~T}$ Nb3Sn Dipole HD2", IEEE Trans. Appl. Sipercond., vol. 18, no. 2, June 2008, pp. 277-280.

[9] S. Feher; B. Bordini; R. Carcagno; A. Makulski; D.F. Orris; Y.M. Pischalnikov; C. Sylvester; M. Tartaglia; "Sudden flux change studies in high field superconducting 
accelerator magnets", IEEE Trans. Appl. Supercond., vol 15, no. 2, June 2005, p.1591.

[10] A.F. Lietzke, et al., "Test results for RD3c, a Nb3Sn, racetrack dipole", IEEE Trans Appl. Supercond., Houston, 2002, pp. 1292-1296.

[11] A.F. Lietzke, et al., "Differentiation of Performance-Limiting Voltage Transients During Nb3Sn Magnet Testing", AIP conference proceedings., vol 824B, 2006, pages 550-557.

[12] J. Lizarazo, et al., "Use of High Resolution DAQ System to Aid Diagnosis of HD2b, a High Field Nb3Sn Dipole", presented at 2008 Applied Superconductivity Conference, Chicago, IL, USA, August 17-22, 2008. 
